\title{
Editorial
}

\section{The purpose of vocational rehabilitation: enhancing employment outcomes for those with the greatest need}

In this issue of the Journal of Vocational Rehabilitation a wide range of articles is presented. However, they all focus on one overriding area of importance: how do we promote quality employment outcomes for persons with significant disabilities?

Quality employment outcomes include competitive wages, good fringe benefits, including health insurance, long-term retention, flexibility in work schedule and the opportunity to get on a career path. For most persons with truly significant disabilities this level of employment outcome has not consistently occurred in rehabilitation programs around the world. Yet this is the avowed purpose of programs which embrace supported employment, transition from school to work, assistive technology and other rehabilitation approaches.

While supported employment programs have been able to generate employment outcomes for participants which are superior to those produced by segregated employment programs, in absolute terms (Rehabilitation Services Administration, 1995), many supported employment programs still yield employment outcomes that have fallen short of initial expectations. Lack of earnings and fringe benefits, integration in the workplace, employer attitudes, job retention and job satisfaction remain issues of concern in supported employment program evaluation. Furthermore, the limited number of hours worked (with an average of 25 $\mathrm{h}$ /week) is a stumbling block to greater prosperity.

In the US, the Rehabilitation Services Administration's data in 1995 indicated that $28 \%$ of persons in supported employment did not work at the minimum wage level of at least $\$ 4.50 \mathrm{US} / \mathrm{h}$. This is based on a number of 18000 vocational rehabilitation closures which is far below the overall national totals in supported employment of 140000 persons. Supported employment earnings have been reported to be $\$ 107 /$ week, on an average basis per client. While this is a several hundred percent increase over wages earned prior to entering the program, annual wages in the range of $\$ 5000-\$ 6000$ are certainly not consistent with the program's intent to enable individuals to pursue meaningful careers. In addition, such heavy reliance on part-time jobs usually results in individuals with disabilities receiving few fringe benefits such as healthcare or paid vacation.

The opportunity for individuals to participate in the social network of the workplace is one of the major values underlying supported employment. Unfortunately, we know that many supported employment participants have been unable to take full advantage of available inclusion opportunities. Complex issues related to the definition of inclusion and appropriate measurement strategies have inhibited the development of ef- 
fective strategies designed to increase the overall level of integration experienced by consumers.

A commitment to employment opportunities implies that all individuals who can benefit from vocational rehabilitation should have equal access to quality employment programs that are equipped to respond to their preferences and needs. However, many excellent rehabilitation programs such as supported employment only have the resources to serve a small percentage of individuals who could benefit from the supports and services offered through local provider agencies. Persons with severe mental retardation, severe mental illness, cerebral palsy, or autism remain underrepresented in competitive employment programs in relation to their overall level of participation in adult day programs (Snyder et al., 1996; Budde et al., 1997). Individuals who possess a specific disability, display severe inappropriate behaviors, or are merely viewed as too challenging or expensive to serve have been historically excluded from supported employment programs in many areas.

To be truly successful, rehabilitation programs must allow those persons with the greatest support needs to equally access and benefit from their services. However, administrative, programmatic and attitudinal barriers have combined to limit or unnecessarily exclude certain groups of individuals from participation in vocational rehabilitation programs.

The underrepresentation of persons with severe disabilities in competitive employment seems to be due to a lack of effective service delivery technologies, low expectations on the part of professionals and employers and government policies that merely allow, rather than promote, the inclusion of persons with severe disabilities into the competitive workplace. There are at least four groups which are often viewed as unserved or underserved, which include:

1. Individuals with the most severe disabilities. In the 1992 Rehabilitation Act Amendments, Congress revised the target population for the supported employment program from individuals with severe disabilities to those with the most severe disabilities. This change was made in part because those individuals who are most in need of long-term supports to maintain competitive employment were under represented among program consumers.

2. Selected disability groups. Since its inception, supported employment has primarily served individuals with mental retardation (over one-half of all participants) and individuals with severe and persistent mental illness (over one-quarter of all participants). Although supported employment has been demonstrated as a viable alternative for individuals with other types of severe disabilities, participation from some groups who could benefit has been very limited. Consumers with other types of disabilities who appear to be under represented include cerebral palsy and other physical disabilities, brain and spinal cord injury, autism and deaf-blindness.

3. Racial and ethnic minorities and women. Women and minorities with disabilities often face a dual handicap in society and in the rehabilitation programs. Differential treatment of women and minorities have been found in the rehabilitation system for many service indicators, such as eligibility determination, placement in academic training, case service expenditures, successful closures and earnings at closure.

4. Waiting lists for services. Another indicator of unserved populations are the existing waiting lists for services. For most agencies, the majority of waiting list consumers in the US are currently being served in sheltered work or other day programs; however, approximately one-quarter of potential supported employment consumers were not in any day services or were coming from school programs. Without a better understanding of the barriers which individuals with disabilities face in accessing supported employment services, competitive employment will remain an unattainable objective for the many individuals with extensive support needs.

The quality of vocational rehabilitation programs and their success in promoting meaningful 
competitive employment is an overriding challenge we face as this century draws to a close. We must bring together the best of what we know and lift up all persons with disabilities who wish to work into the labor force. To not do so would continue us down a road of unfulfilled potential.

Paul Wehman

\section{References}

Budde, J., Youngbauer, J., Snyder, J., 1997. Underserved consumers with mental retardation. University of Kansas: Lawrence, Kansas.

Rehabilitation Services Administration closure report for 1995: Washington, D.C.

Snyder, J., O'Neil, T., Temple, L., Crowell, R., 1996. Psychiatric disabilities: concerns, problem solutions. Boston, MA: Boston University. 